\title{
Microbiota and Cancer
}

\section{Mikrobiyota ve Kanser}

Tarık Salman ${ }^{1}$, Umut Varol ${ }^{1}$, İbrahim Yıldız ${ }^{1}$, Yüksel Küçükzeybek ${ }^{1}$, Ahmet Alacacıoğlu ${ }^{1}$

1.İzmir Katip Çelebi Üniversitesi Atatürk Eğitim ve Araştırma Hastanesi Tıbbi Onkoloji Kliniği

Dergiye Ulaşma Tarihi: 21.06.2015 Dergiye Kabul Tarihi: 11.08.2015 Doi: 10.5505/aot.2015.49368

\section{ÖZET}

Mikrobiyota vücudumuzu paylaştığımız tüm mikroorganizmaların tanımıdır.Mikrobiyota bir ekosistem olup insan sağlığında besinlerin ve K vitaminin sağlanması, sindirimde rol ynar. Mikrobiyota immün fonksiyonu biyolojik aktif metabolitler sayesinde etkiler ve mikrobiyotanın değişimi (disbiyozis) pek çok hastalığın gelişiminde yer alır. Son yapılan çalışmalar mikrobiyotanın immün kaçış mekanizması sayesinde karsinojenezisin önemli bir parçası olduğunu ve kanser tedavisinde de etkili olabileceğini göstermiştir.

Anahtar kelimeler: Mikrobiyota, kanser

Microbiota is all microorganisms that share our body and microbiota ecosystem plays an important role in human health such as spplying nutrients, $\mathrm{K}$ vitamin, digestion, Microbiota affects many immun functions by biological molecules and change of the microbiota (disbiosis) has a critical roles development of multple diseases. Recently it has been reported that microbiota is an important part of carcinogenesis cause by immun evasion and has effect on the treatment of cancer.

Key words: Microbiyota, cancer.

\section{Giriş}

Mikrobiyota bedenimizi paylaşan kommensal, simbiyotik ve patojenik mikroorganizmaların oluşturduğu ekolojik yapıdır $(1,2)$. Mikrobiyom ise bu çevrede yaşayan mikroorganizmaların toplam genomunu olarak tariflenmiştir fakat günümüzde mikrobiyota ve mikrobiyom literatürde sinonim olarak kabul edilmektedir. $(3,4)$. İnsan vücudunda toplam insan hücresinden yaklaşık olarak on kat fazla mikrobiyal hücre vardır ve bunlar insan genomundan 150 kat fazla gen içerir.Bu mikrobiyal hücrelerin toplam ağırlı $\breve{g}_{1}$ ise sadece 200 gramdır (5). Çevredeki mikroorganizmaların sadece $\% 1$ kadarı kültüre edilebilmekte ve sadece bunlardan tek genom analizi yapabilmektedir. Metagenomik çalışmalarla çevredeki tüm mikroorganizmaların genomunun toplanması ve analiz edilmesi sonucunda genomik analizi yapılamayan çevredeki mikroorganizmaların \%99'luk kısmınında tek genom analizi yapılmış gibi değerlendirilebilmesi mümkün olmuştur (6). Mikrobiyotanın insan sağlı̆g 1 ve kanser dahil pek çok hastalıkla ilişkisinin gösterilmesi ile bu alanda çalışmalar hız kazanmış ve mikrobiyotanın yeni bir organ olarak değerlendirilmesi gerektiği görüşü ortaya çıkmıştır (7). Mikrobiyota yaşamın ilk yılında gıda alımının başlaması ile beraber oluşmaya başlar ve ilk yılın sonunda erişkin dönem profiline benzer yap1 oluşur. $\mathrm{Bu}$ yap1 herkeste farklıl1k gösterir (8). İnsan barsak mukozası epitelyal hücreler, lamina propia ve musacularis mukozadan oluşur ve $10^{14}$ mikroorganizma burada kolonize olmuştur. $\mathrm{Bu}$ sayı tüm insan hücrelerinden on kat daha fazladır (9). Doğumdan hemen sonra mikrobiyota oluşmaya başlar ve yenidoğan döneminde yaklaşı $\quad 1000$ çeşit mikroorganizma olur. Bunların çoğunluğu genomu saptanamayan anaerobik organizmalardır. Yenidoğanların arasında da mikrobiyota farklılık gösterir ve erişkin benzeri mikrobiyota yaşamın ilk yılının sonunda şekillenmiş olur (10). İntestinal mikrobiyotanın kompozisyonunun farklilık göstermesinde intestinal motilite, $\mathrm{pH}$, redoks durumu, nutrientler, sekresyonlar (asit, safra,mukus, enzimler), antibiotik kullanımı, yaş, kötü beslenme ve yaşam şekli etkin rol oynamaktadır (11). Mikrobiyota ile insan kommensal bir yaşam sürmektedir. Barsak mikrobiyotası temel nutriyentlerin sağlanmasında, $K$ vitamini sentezinde, selülozun sindirilmesinde, anjiyojenesiz 
başlamasında ve enterik sinir iletiminde rol oynamaktadır (12). Mikrobiyota mukozal bariyer direncini artırarak mukozal dokuları antijen ve patojenlerden korur. Probiyotikler bu aşamada yardımcı rol oynamaktadır (12). Mikrobiyotanın konakçı immün sistemine bu derecede önemli desteğine rağmen bu ekosistemdeki anormal değişiklikler sonucunda gelişen disbiyozis durumunda ise alerji, inflamatuvar hastalıklar, obesite, diyabet mellitus ve kanser gelişimi hızlanır $(14,15)$.

\section{ve immün düzenleyici rolü}

Mikrobiyotanın lokal inflamasyon Mikrobiyota aracili epitelyal immünitenin modülasyonu ile mekanizmalar tanımlanmaya başlanmıştır. Barsak ilişkili lenfoid dokuların (GALTs) tam maturasyonu, mukozada IgA sekrete eden hücrelerin ve aktive $\mathrm{T}$ hücrelerin mukozada toplanması için gerekli olan mikrobiyota ilişkili sinyaller doğumdan itibaren gereklidir $(16,17)$. Mikrobiyota tarafindan fermentasyonla oluşturulan kısa zincirli yağ asitleri (KZYA) G-protein aracılığıyla mukozal immüniteyi etkiler. KZYA enterositlerde interlökin -8 (IL18) üretimini tetikler (18). KZYA regulatuvar $\mathrm{T}$ (treg) hücrelerini direk etkiler ve onların büyüme ve fonksiyonlarını düzenler (19). Mikrobiyotanın önemli bakterilerinden olan bakteriodes frajilis kapsüler polisakkarit A ile IL-10 sekrete eden Treg diferensiyasyonunu sağlar ve bu mekanizma kolit gelişimininde koruyucu özelliktedir (20). Cilt mikrobiyotanın zengin bir parçasıdır ve farklı nişlerden oluşur. İntestinal bölgenin aksine ciltte mikrobiyota lenfoid dokuya ihtiyaç duymaz. Ciltte mikrobiyata IL-1 $\alpha$ üretimi ile dermiste T elper 17 (Th17) ve Th1 aktivasyonunun devamin sağlar (21). Lokal bariyere olan katkısı dışında mikrobiyota sistemik immünitenin devamında önemlidir. Farelerde mikrobiyotanın olmaması pek çok anatomik bölgede direnç gösterilemeyen enfeksiyonların gelişimi, otoimmün hastal1klar, kemoterapi direnci, immün tedavilere azalmış cevap ve ölümle sonuçlanmaktadır $(22,23)$. Mikrobiyota pek çok bölgede olmasına rağmen mikrorganizma sayısının fazlalığı nedeniyle intestinal mikrobiyota sistemik immün yanıtta daha önemlidir. Farklı bölgelerdeki mikrobiyota birbirini immün yanıtlar aracığı ile fonksiyonel olarak etkiler (24). Klasik teorinin aksine intestinal bariyer mikroorganizmalar için kesin bir bariyer değildir. Mikroorganizmalar veya onların ürünleri bariyeri geçip inflamtuvar bir yanıt başlatmaktadır (25). Mikrobiyotanın immün yanıtta etkinliğinde ürettiğ aktif moleküllerden IL-1, IL-18, interferonlar, TNf, IL-10, serum amiloid A en etkin olanlarıdır (26).

\section{Mikrobiyota ve Hastalıklar}

Mikrobiyotanın kompozisyonun bozulması ile hastalıklar arasında ilişki vardır. Gelişmiş ülkelerde daha sik görülen inflamutuvar bağırsak hastalıkları (IBH) ile mikrobiyota sonucunda gelişen kronik intestinal inflamasyon arasında güçlü ilişki vardır $(27,28)$. Mikrobiyotaya karşı gelişen Th1 aracılı artmış sitokin yanıtı bu süreçte aktif rol oynamaktadır ve ek olarak makrofajlar tarafından mikrobiyotanın tanınmasındaki bozulmalarda IBH patojenezine katkıda bulunmaktadir (29). IBH olan ülseratif kolit (ÜC) hastalarında mikrobiyotanın üyelerinden olan laktobasillerin düzeyi hastalığın remisyon ve aktif dönemlerinde farklılık gösterir (30). E.coli ve bakteriyal TLR2 yükünün artmas1 ÜC hastalarında hastalık şiddetiyle ilişklidir. TLR2 ile nötrofil ve T hücre aktivasyonu ile IL-12, IL-23 hiperprodüksiyonu olur ve sonucunda kolit gelişir (31). ÜC hastaları normal popülasyona göre farklı genetik özellikler taşımaktadır ve bu genetik değişiklikler ile mikrobiyotanın değişiklikleri paralellik göstermektedir (32). Diğer IBH olan Crohn Hastalığ $(\mathrm{CH})$ otoimmün bir hastalıktır. Fekal mikroflora aktif ve inaktif $\mathrm{CH}$ hastalarında enterobakterler açısından farklıdır (33). $\mathrm{CH}$ olanlar ve onların sağlıklı akrabaları arasında butirat oluşturan bakteriler ve müsin degarade eden bakteri sayıları farklıdır (34). Mikrobiyota obesite gelişiminde etkindir. Yüksek yağ içeren diyet alanlarda mikrobiyota bakteriyal kompozisyonu değiştirir. Örneğin obes hastalarda mikrobiyotada firmukutes ve bakteriodes oranı değişmekte ve bu kronik inflamatuvar süreçte etkin olmaktadır $(35,36)$. Tip1 ve Tip2 diyabet gelişiminde infantil dönemdeki beslenme özelliklerine bağlı olarak değişen mikrobiyota önemlidir (37). Tip 1 diyabet gelişiminde bozulmuş intestinal bariyer ve buna bağlı gelişen mukozal immünite değişiklikleri pankreas adacık hücrelerinin dekstrüksiyonunda rol oynarlar (38). Butirat ve müsin intestinal bütünlüğün devamı için esansiyeldir. Tip 1 diyabetli çocuklarda klostridyum, bakteriodes, veinello sayıları 
artmış iken, laktabasillus, bifidobakteriyum prevotella düzeyleri anlamlı olarak düşük bulunmuştur (39). Bakteri membran lipopolisakkaritlerine bağlı gelişen endotoksemi tip 2 diyabet gelişimine katkıda bulunmaktadır ve antibiyotik tedavisi alan hayvan modellerinde insülin direnci ile diyabet tablosu düzelmektedir (40). Karaciğer ile intestinal sistem metabolizmada direk olarak birbiriyle ilişkilidir. Mikrobiyota üretiminin detoksifikasyonu ve desensitizasyonunda karaciğer birinci basamaktır. Non-alkolik hepatit (NASH) gelişiminde mikrobiyotanın özellikle ince bağırsakta aşırı gelişimi olmakta ve antibiyotik tedavisi ile NASH kliniğinde düzelme olmaktadır. Mikrobiyota kaynaklı $\mathrm{TNF} \alpha$ bu süreci yönetmektedir (41). Mikrobiyota kardiyovasküler hastalıklarla direk ilgilidir. Mikrobiyotanın diyetteki kolinlerden ürettiği trimetilamin (TMA) proaterojenik bir molekül olarak kardiyovasküler hastalıkların (KVH) patojenezine katılır (42). Bakteri kolonizasyonundaki farklılıklar ve intestinal bariyer bozulmasi sonucunda bakteriyel toksinlerin neden olduğu endotelyal hasar $\mathrm{KVH}$ gelişimi ve devamında önemlidir (43). Hiperkolesterolemi özellikle laktobasillerin sayıca artması durumunda şiddetlenmektedir ve kolesterol KVH ile direk ilişkilidir (44). Otizm hastalarında genetik ve çevresel faktörlerin yanında diyare, dispepsi gibi gastrointestinal semptomlarda yer alır (45). Bağırsak-beyin aksındaki patolojiler otizm gelişimine katkıda bulunmaktadır (46). Mikrobiyota merkezi sinir sistemi hücreleri ile nöral, endokrin ve immün yollar aracıllı̆g ile iletişimde olmakta ve beyin fonksiyon ve davranışı etkilemektedir (47).

\section{Mikrobiyota ve Kanser}

Tümörlerin progresyonu ile invazyonu inflamasyon ve antitümör immün yanitlara bağlıdır. Kanser olgularının \%15'inde enfeksiyöz ajanlar veya enfeksiyon ilişkili inflamasyonla ilişki vardır (48). Mikrobiyotanin disbiyozis ve intestinal bariyerin yıkımı sonrası hemopoetik hücrelerle direk teması kanserojeneziste inflamatuvar süreci başlatır (49, 50). IL-18'in mukozal koruyucu etkisi vardır ve IL-18 üretimi olmayan farelerde gelişen disbiyozis sonucunda kimyasal uyarılarla kolon kanseri gelişimi olmaktadır (51). Butirat bir KZYA olup intestinal sistemde diyetteki fiberlerden bakteriler tarafindan üretilir ve intestinal hücrelerdeki GPR109a ile IL-18 üretimini sağlar.Butirat ayrıca doğrudan makrofaj, T hücre ve dentirik hücreleri uyarır (52). KZYA Treg hücreleri uyararak kolonik inflamasyon ve karsinojenezisi bask1layan IL-10 üretimini arttırır (53). IL-22, STAT3 aracılığı ile lamina propiadaki lenfoid dokuda üretilir ve intestinal bariyeri bakteriyel etmenlerden korur ve antikarsinojeniktir (54). IL-18 ve Il-22 ekspresyonu engellenen hayvan modellerinde bakteriyel endotoksinler karsinojenezisi tetiklemektedir (55). Pek çok mikrobiyal etmenin özellikle, entereokokus fekalis, enterotoksijenik bakteriodes frajilis, enteropatojenik E.koli, fusobakteriyum spp ve streptokokus gallolitukusun karsinojeneziste rolü tanımlanmıştır $(56,57)$. Odaribakter ve akkermanya kolonizasyonu kolon tümörü geliştirilen hayvan modellerinde mikrobiyotada artmış oranda bulunmaktadır ve kolorektal kanser gelişimi ile ilişkili bulunmuştur (58). Fusobakteriyum nükleatum E-kadherine bağlanarak wnt/katenin yolak aktivasyonu yapmakta ve tümör proliferasyonunda rol oynamaktadir (59). Prekanseröz poliplerin oluşturulduğu hayvan modellerinde sağlıklı dokuya göre poliplerde transmukozal bakteriyel translokasyon daha fazla bulunmuştur. $\mathrm{Bu}$ modellerde poliplerin progresyonu için translokasyon gösteren mikrobiyotada ekspresyonu artan IL-6, IL-11, IL-23 ve IL-22 gerekmekte ve bu kanser proliferasyonunu hizlandirmaktadır (60). Mikrobiyota sadece lokal etki ile karsinojenezisi uyarmamaktadır. Helikobakter hepatikusun artmış kolonizasyonu APCmin/+/Rag2-/- farelerde meme, prostat ve hepatoselüler kanser gelişiminde rol oynadığı gösterilmiştir (61). Atm-1- farelerde mikrobiyota değişimi ile çevresel faktörlerin deneysel kullanımı ile lenfoma gelişimi gözlenmiştir (62). Mikrobiyotanın uzak organlardaki karsinojenezise tümör nekrotizan faktör (TNF) tarafindan düzenlenen sistemik inflamasyon, oksidatif stres ve epiteyal genotoksite ile katkıda bulunduğu tanımlanmıştır (63). Antibiyotik kullanımına bağlı değişen mikrobiyota östrojen metabolizmasında değişimlere sebeb olmakta ve meme kanseri gelişiminde bir risk faktörü olmaktadır (64). Antibiyotik kullanımı sonucu gelişen kolondaki c.albicans kolonizasyonu mikrobiyotayı bozmaktadır. $\mathrm{Bu}$ bozulma 
sırasında akciğerlerde alerjik etkileri yanında tümör proliferatif etkileride olan prostaglandinler ve makrofaj kolonizasyonu olmaktadır (65).

Son zamanlarda yapılan çalışmalarda mikrobiyotanın kemoterapi ve immünoterapiye verilen yanıtı tümör mikroçevresindeki myeloid kökenli hücreler aracılığıyla etkilediğini göstermiştir. CD40 ile olan dentritik hücre aktivasyonu, IL-12 üretimi, CD8+ T hücreli gelişen adoptif immünoterapi tümörojenesizte etkindir. İntratümöral $\mathrm{CpG}-$ oligodeoksinüleotid ve IL-10 sinyal nötralizsayonu yapılarak uygulanan immünoterapi sağlıklı farelerde etkin olurken mikrobiyotanın olmadığı farelerde belirtilen mekanizmaların olmaması nedeniyle etkisiz olmaktadır. Mikrobiyotanın olmadığı farelerde gavaj yoluyla verilen lipopolisakkaritler ile kemoterapi yanıtı azalır, fekal gram pozitif bakteri kolonizasyonu ve $\mathrm{TNF} \alpha$ düzeyleri artar. Aynı modelde uygulanan subkütan siklofosfamid ve okzaliplatinin etkisi antibiotik ile mikrobiyotanın bozulması sonucunda azalmaktadır (66). Antibiyotik verilen farelerde sisplatinin DNA ile etkileşimi bozulur, genotoksik etkisi olmaz ve immün aracılı hücre ölümü gerçekleşmez (67).

Reaktif oksijen metabolitleri okzaliplatin etkinliğinde önemlidir. Mikrobiyotanın antibiyotik ile ortadan kaldırıldığ farelerde bu metabolitlerin düzeyi azalmakta ve okzaliplatin antitümör etkisi azalmaktadır (68). Adoptif immünoterapi ve tüm vücut radyoterapi uygulanan hastalarda intestinal mikrobiyota,değişimleri ile tedavilerinin etkinliğini arttırmaktadır (69). Siklofosfamidin etkinliğide antibiyotik ile mikrobiyotanın bozulduğu farelerde mikrobiyota kaynaklı Th1 ve Th17 düzeylerinin düşük olması sonucu azalmaktadır (70).

\section{Sonuç:}

Mikrobiyota güncel araştırmalar doğrultusunda artık yeni bir organ olarak değerlendirilmeye başlanmıştır. Pek çok hastalıkta olduğu gibi kanser üzerine olan etkileride araştırılmaya başlanmış ve gelecekte mikrobiyotanın karsinojeneziste rolünün anlaşılması ile kanser tedavisindeki yerinin artacağına dair görüşler artmıştır.

\section{Çıkar Çatışması: Yok}

\section{Referanslar}

1. Lederberg, J; McCray, AT (2001). "'Ome Sweet 'Omics-a genealogical treasury of words". Scientist 15: 8.

2. "The NIH Human Microbiome Project". Genome $\begin{array}{llll}\text { Res } & 19 & \text { (12): } 2317-2323 . & \end{array}$ doi:10.1101/gr.096651.109.

3. Turnbaugh, P.J.; Ley, R.E.; Hamady, M.; FraserLiggett, C.M.; Knight, R.; Gordon, J.I. (2007). "The Human Microbiome Project". Nature 449: 804-810.

4. Ley, R.E.; Peterson, D.A.; Gordon, J.I. (2006). "Ecological and Evolutionary Forces Shaping Microbial Diversity in the Human Intestine". Cell 124: 837-848.

5. Coyle, MD, Walter J. "The Human Microbiome: The Undiscovered Country". p. 16. Retrieved 2 March 2012.

6. Handelsman, J.; Rondon, M. R.; Brady, S. F.; Clardy, J.; Goodman, R. M. (1998). "Molecular biological access to the chemistry of unknown soil microbes: A new frontier for natural products". Chemistry \& Biology 5 (10): R245-R249.

7. Clarke G, Stilling RM, Kennedy PJ, Stanton C, Cryan JF, Dinan TG Minireview: Gut microbiota: the neglected endocrine organ. Mol Endocrinol. 2014 Aug;28(8):1221-38. doi: 10.1210/me.20141108.

8. Palmer, C.; Bik, E.M.; DiGiulio, D.B.; Relman, D.A.; Brown, P.O. Development of the human infant intestinal microbiota. PLoS. Biol. 2007, 5, 15561573

9. Clark, J.A.; Coopersmith, C.M. Intestinal crosstalk: A new paradigm for understanding the gut as the "motor" of critical illness. Shock 2007, 28, 384-393.

10. Palmer, C.; Bik, E.M.; DiGiulio, D.B.; Relman, D.A.; Brown, P.O. Development of the human infant intestinal microbiota. PLoS. Biol. 2007, 5, 15561573.

11. Gerritsen, J.; Smidt, H.; Rijkers, G.T.; de Vos, W.M. Intestinal microbiota in human health and disease: The impact of probiotics. Genes Nutr. 2011, 6, 209240.

12. Guarner, F.; Malagelada J.R. Gut flora in health and disease. Lancet 2003, 361, 512-519

13. Ulluwishewa, D.; Anderson, R.C.; McNabb, W.C.; Moughan, P.J.; Wells, J.M.; Roy, N.C. Regulation of tight junction permeability by intestinal bacteria and dietary components. J. Nutr.2011, 141, 769-776

14. Tsuji, M.; Suzuki, K.; Kinoshita, K.; Fagarasan, S. Dynamic interactions between bacteria and immune cells leading to intestinal IgA synthesis. Semin. Immunol. 2008, 20, 59-66.

15. Tuohy, K.M.; Hinton, D.J.; Davies, S.J.; Crabbe, M.J.; Gibson, G.R.; Ames, J.M. Metabolism of Maillard reaction products by the human gut microbiota-implications for health. Mol. Nutr. Food Res. 2006, 50, 847-857.

16. Belkaid, Y. and Hand, T. W., Role of the microbiota in immunity and inflammation. Cell 2014. 157: 121141.

17. Round, J. L. and Mazmanian, S. K., Inducible Foxp3+ regulatory T-cell development by commensal bacterium of the intestinal microbiota. Proc. Natl. Acad. Sci. USA 2010. 107: 12204-12209

18. Kalina, U., Koyama, N., Hosoda, T., Nuernberger, H., Sato, K., Hoelzer, D., Herweck, F. et al., Enhanced production of IL-18 in butyrate-treated 
intestinal epithelium by stimulation of the proximal promoter region.Eur. J. Immunol. 2002. 32: 26352643.

19. Smith, P. M., Howitt, M. R., Panikov, N., Michaud, M., Gallini, C. A., Bohlooly, Y. M., Glickman, J. N. et al., The microbial metabolites, shortchain fatty acids, regulate colonic Treg cell homeostasis. Science 2013.341: 569-573.

20. Mazmanian, S. K., Round, J. L. and Kasper, D. L., A microbial symbiosis factor prevents intestinal inflammatory disease. Nature 2008. 453: 620-625

21. Naik, S., Bouladoux, N., Wilhelm, C., Molloy, M. J., Salcedo, R., Kastenmuller, W., Deming, C. et al., Compartmentalized control of skin immunity by resident commensals. Science 2012. 337: 1115-1119

22. Belkaid, Y. and Naik, S., Compartmentalized and systemic control of tissue immunity by commensals. Nat. Immunol. 2013. 14: 646-653.

23. Chervonsky, A. V., Microbiota and autoimmunity. Cold Spring Harb. Perspect.Biol. 2013. 5

24. Ding, T. and Schloss, P. D., Dynamics and associations of microbial community types across the human body. Nature 2014. 509: 357-360

25. Venkatesh, M., Mukherjee, S., Wang, H., Li, H., Sun, K., Benechet, A. P.,Qiu, Z. et al., Symbiotic bacterial metabolites regulate gastrointestinal barrier function via the xenobiotic sensor PXR and Toll-like receptor 4. Immunity 2014. 41: 296-310.

26. Larsson, E., Tremaroli, V., Lee, Y. S., Koren, O., Nookaew, I., Fricker,A., Nielsen, J. et al., Analysis of gut microbial regulation of host gene expression along the length of the gut and regulation of gut microbial ecology through MyD88. Gut 2012. 61: $1124-1131$.

27. Fuentealba, C.; Figuerola, F.; Estevez, A.M.; Bastias, J.M.; Munoz, O. Bioaccessibility of lignans from flaxseed (Linum usitatissimum L.) determined by Single Batch in vitro simulation of the digestive Pprocess. J. Sci. Food. Agric. 2014, 94, 1729-1738

28. Jostins, L.; Ripke, S.; Weersma, R.K.; Duerr, R.H.; McGovern, D.P.; Hui, K.Y.; Lee, J.C.; Schumm, L.P.; Sharma, Y.; Anderson, C.A.; et al. Hostmicrobe interactions have shaped the genetic architecture of inflammatory bowel disease. Nature 2012, 491, 119-124

29. Hoentjen, F.; Welling, G.W.; Harmsen, H.J.; Zhang, X.; Snart, J.; Tannock, G.W. Lien, K.;Churchill, T.A.; Lupicki, M.; Dieleman, L.A. Reduction of colitis by prebiotics in HLA-B27 transgenic rats is associated with microflora changes and immunomodulation. Inflamm. Bowel Dis. 2005, 11, 977-985

30. Bullock, N.R.; Booth, J.C.L.; Gibson, G.R. Comparative composition of bacteria in the human intestinal microflora during remission and active ulcerative colitis. Curr. Issues Intest. Microbiol.2004, 5, 59-64.

31. Kamada, N.; Hisamatsu, T.; Okamoto, S.; Sato, T.; Matsuoka, K.; Arai, K.; Nakai, T.; Hasegawa, A.; Inoue, N.; Watanabe, N.; Akagawa, K.S.; Hibi, T. Abnormally differentiated subsets of intestinal macrophage play a key role in Th1-dominant chronic colitis through excess production of IL-12 and IL-23 in response to bacteria. J. Immunol. 2005, $175,6900-6908$
32. Lepage, P.; Haesler, R.; Spehlmann, M.E.; Rehman, A.; Zvirbliene, A.; Begun, A.; Ott, S.; Kupcinskas, L.; Dore, J.; Raedler, A.; Schreiber, S. Twin study indicates loss of interaction between microbiota and mucosa of patients with ulcerative colitis. Gastroenterology 2011, 141, 227-236

33. Seksik, P.; Rigottier-Gois, L.; Gramet, G.; Sutren, M.; Pochart, P.; Marteau, P.; Jian, R.; Dore, J.Alterations of the dominant faecal bacterial groups in patients with Crohn's disease of the colon.Gut 2003, 52, 237-242.

34. Joossens, M.; Huys, G.; Cnockaert, M.; de Preter, V.; Verbeke, K.; Rutgeerts, P, Vandamme, P, Vermeire, S. Dysbiosis of the faecal microbiota in patients with Crohn's disease and their unaffected relatives. Gut 2011, 60, 631-637.

35. Ding, S.L.; Chi, M.M.; Scull, B.P.; Rigby, R.; Schwerbrock, N.; Magness, S.; Jobin, C.; Lund, P.K. High-fat diet: Bacteria interactions promote intestinal inflammation which precedes and correlates with obesity and insulin resistance in mouse. PLoS ONE 2010, 5, e12191.

36. Armougom, F.; Henry, M.; Vialettes, B.; Raccah, D.; Raoult, D. Monitoring bacterial community of human gut microbiota reveals an increase in Lactobacillus in obese patients and Methanogens in anorexic patients. PLOS ONE 2009, 4, e7125

37. Burcelin, R.; Serino, M.; Chabo, C.; Blasco-Baque, V.; Amar, J. Gut microbiota and diabetes:From pathogenesis to therapeutic perspective. Acta Diabetol. 2011, 48, 257-273

38. Nara, N.; Alkanani, A.K.; Ir, D.; Robertson, C.E.; Wagner, B.D.; Frank, D.N.; Zipris, D. The role of the intestinal microbiota in type 1 diabetes. Clin. Immunol. 2013, 146, 112-119.

39. Murri, M.; Leiva, I.; Gomez-Zumaquero, J.M.; Tinahones, F.J.; Cardona, F.; Soriguer, F.; QueipoOrtuno, M.I. Gut microbiota in children with type 1 diabetes differs from that in healthy children: A case-control study. BMC Med. 2013, 11, doi:10.1186/1741-7015-11-46.

40. Amar, J.; Chabo, C.; Waget, A.; Klopp, P.; Vachoux, C.; Bermudez-Humaran, L.G.; Smirnova, N.;Berge, M.; Sulpice, T.; Lahtinen, S.; et al. Intestinal mucosal adherence and translocation of commensal bacteria at the early onset of type 2 diabetes: Molecular mechanisms and probiotic treatment. EMBO Mol. Med. 2011, 3, 559-572.

41. Small intestinal bacteria overgrowth decreases small intestinal motility in the NASH rats. World $J$. Gastroenterol. 2008, 14, 313-317.

42. Sandek, A.; Bauditz, J.; Swidsinski, A.; Buhner, S.; Weber-Eibel, J.; von Haehling, S.; Schroedl, W.;Karhausen, T.; Doehner, W.; Rauchhaus, M.; et al. Altered intestinal function in patients with chronic heart failure. J. Am. Coll. Cardiol. 2007, 50, $1561-1569$.

43. Krack, A.; Sharma, R.; Figulla, H.R.; Anker, S.D. The importance of the gastrointestinal system in the pathogenesis of heart failure. Eur. Heart J. 2005, 26, 2368-2374

44. Bosch, M.; Fuentes, M.C.; Audivert, S.; Bonachera, M.A.; Peiro, S. Cune,J.Lactobacillus plantarum CECT 7527, 7528 and 7529: Probiotic candidates to reduce cholesterol levels. J. Sci. Food Agric.2014, 94, 803-809. 
45. Adams, J.B., Johansen, L.J.; Powell, L.D.; Quig, D.; Rubin, R.A. Gastrointestinal flora and gastrointestinal status in children with autismcomparisons to typical children and correlation with autism severity. BMC Gastroenterol. 2011, 11.

46. Cryan, J.F.; Dinan, T.G. Mind-altering microorganisms: The impact of the gut microbiota on brain and behaviour. Nat. Rev. Neurosci. 2012, $13,701-712$

47. Heberling, C.A.; Dhurjati, P.S.; Sasser, M. Hypothesis for a systems connectivity model of autism spectrum disorder pathogenesis: Links to gut bacteria, oxidative stress, and intestinal permeability. Med. Hypotheses 2013, 80, 264-27

48. de Martel, C., Ferlay, J., Franceschi, S., Vignat, J., Bray, F., Forman, D. and Plummer, M., Global burden of cancers attributable to infections in 2008: a review and synthetic analysis. Lancet Oncol. 2012. 13:607-615.

49. Plottel, C. S. and Blaser, M. J., Microbiome and malignancy. Cell Host Microbe 2011. 10: 324-335.

50. Goldszmid, R. S. and Trinchieri, G., The price of immunity. Nat. Immunol. 2012. 13: 932-938.

51. Salcedo, R., Worschech, A., Cardone, M., Jones, Y., Gyulai, Z., Dai, R. M., Wang, E. et al., MyD88mediated signaling prevents development of adenocarcinomas of the colon: role of interleukin 18 . J. Exp. Med. 2010.207: 1625-1636

52. Singh, N., Gurav, A., Sivaprakasam, S., Brady, E., Padia, R., Shi, H., Thangaraju, M. et al., Activation of Gpr109a, receptor for niacin and the commensal metabolite butyrate, suppresses colonic inflammation and carcinogenesis. Immunity 2014. 40: $128-139$

53. Smith, P. M., Howitt, M. R., Panikov, N., Michaud, M., Gallini, C. A.,Bohlooly, Y. M., Glickman, J. N. et al., The microbial metabolites, shortchain fatty acids, regulate colonic Treg cell homeostasis. Science 2013.341: 569-573.

54. Saleh, M. and Trinchieri, G., Innate immune mechanisms of colitis and colitis-associated colorectal cancer. Nat. Rev. Immunol. 2011. 11: 920.

55. Wlodarska, M., Thaiss, C. A., Nowarski, R., HenaoMejia, J., Zhang, J. P., Brown, E. M., Frankel, G. et al., NLRP6 inflammasome orchestrates the colonic host-microbial interface by regulating goblet cell mucus secretion.Cell 2014. 156: 1045-1059

56. Sears, C. L. and Garrett, W. S., Microbes, microbiota, and colon cancer.Cell Host Microbe 2014. 15: 317-328.

57. Zackular, J. P., Baxter, N. T., Iverson, K. D., Sadler, W. D., Petrosino, J. F., Chen, G. Y. and Schloss, P. D., The gut microbiome modulates colon tumorigenesis. mBio 2013. 4: 00692-00713

58. Mira-Pascual, L., Cabrera-Rubio, R., Ocon, S., Costales, P., Parra, A.,Suarez, A., Moris, F. et al., Microbial mucosal colonic shifts associated with the development of colorectal cancer reveal the presence of different bacterial and archaeal biomarkers. $J$. Gastroenterol. 2014. DOI:10.1007/s00535-014-0963

59. Sears, C. L. and Garrett, W. S., Microbes, microbiota, and colon cancer.Cell Host Microbe 2014. 15: 317-328.

60. Bongers, G., Pacer, M. E., Geraldino, T. H., Chen, L., He, Z., Hashimoto, D., Furtado, G. C. et al.,
Interplay of host microbiota, genetic perturbations, and inflammation promotes local development of intestinal neoplasms in mice. J. Exp. Med. 2014. 211: 457-472.

61. Poutahidis, T., Cappelle, K., Levkovich, T., Lee, C. W., Doulberis, M., Ge, Z., Fox, J. G. et al., Pathogenic intestinal bacteria enhance prostate cancer development via systemic activation of immune cells in mice. PLoS ONE 2013. 8: e73933

62. Yamamoto, M. L., Maier, I., Dang, A. T., Berry, D., Liu, J., Ruegger, P.,M.,Yang, J. I. et al., Intestinal bacteria modify lymphoma incidence and latency by affecting systemic inflammatory state, oxidative stress, and leukocyte genotoxicity. Cancer Res. 2013. 73: 4222-4232

63. Westbrook, A. M., Wei, B., Hacke, K., Xia, M., Braun, J. and Schiestl, R.,H., The role of tumour necrosis factor-alpha and tumour necrosis factor receptor signalling in inflammation-associated systemic genotoxicity.Mutagenesis 2012. 27: 77-86.

64. Sergentanis, T. N., Zagouri, F. and Zografos, G. C., Is antibiotic use a risk factor for breast cancer? A meta-analysis. Pharmacoepidemiol. Drug Saf. 2010. 19: 1101-1107

65. Kim, Y. G., Udayanga, K. G., Totsuka, N., Weinberg, J. B., Nunez, G. And Shibuya, A., Gut dysbiosis promotes $\mathrm{M} 2$ macrophage polarization and allergic airway inflammation via fungi-induced PGE(2). Cell Host Microbe 2014. 15: 95-102.

66. Iida, N., Dzutsev, A., Stewart, C. A., Smith, L., Bouladoux, N., Weingarten,,R. A.,Molina, D. A. et al., Commensal bacteria control cancer response to therapy by modulating the tumor microenvironment. Science 2013. 342: 967-970.

67. Laurent, A., Nicco, C., Chereau, C., Goulvestre, C., Alexandre, J., Alves, A., Levy, E. et al., Controlling tumor growth by modulating endogenous production of reactive oxygen species. Cancer Res. 2005. 65: 948-956

68. Laurent, A., Nicco, C., Chereau, C., Goulvestre, C., Alexandre, J., Alves, A., Levy, E. et al., Controlling tumor growth by modulating endogenous production of reactive oxygen species. Cancer Res. 2005. 65: 948-956.

69. Paulos, C. M., Wrzesinski, C., Kaiser, A., Hinrichs, C. S., Chieppa, M., Cassard, L., Palmer, D. C. et al., Microbial translocation augments thefunction of adoptively transferred self/tumor-specific CD8+ T cells via TLR4 signaling. J. Clin. Invest. 2007. 117: 2197-2204

70. Viaud, S., Saccheri, F., Mignot, G., Yamazaki, T., Daillere, R., Hannani, D., Enot, D. P. et al., The intestinal microbiota modulates the anticancer immune effects of cyclophosphamide. Science 2013. 342: 971-976. 